\title{
Practice and Exploration of Reforming Teaching Etiquette to Air Crew
}

\author{
Mo Liu \\ College of Culture and Tourism, Jilin Province Economic Management Cadre College, Changchun \\ City, Jilin Province, China, 130012 \\ 446717864@qq.com
}

Keywords: Air crew; Etiquette; Reform; Practice; Exploration

\begin{abstract}
Service etiquette is one of the required courses for air crew, so students need to master relevant etiquette knowledge and service skills, which should not only remain at learning at the surface level, but also provide students with the practical training opportunity to improve their etiquette skills by combing theories and practice. However, in actual study, due to restriction of the class time and that teachers are uncap able of setting the practical link, students lack practical experience, which directly affects them in adapting to future work and is not beneficial for the long-term development of their work. According to his own teaching experience, the author proposes problems in teaching etiquette to air crew and puts forward corresponding reform measures in order to help the actual training and teaching to air crew.
\end{abstract}

\section{Introduction}

In recent years, the tourism industry has gradually received more attention as the third industry, and people are having higher and higher requirements to life quality, which proposes higher requirements to air crew and ground staffs. In order to adapt to the developing aviation industry, many colleges and universities have set the aviation major, which is also an improvement of existing educational system. Aviation major aims at cultivating professional and comprehensive talents for aviation enterprises so as to provide passengers with high-quality services. Major courses of aviation major include service etiquette, public relations and physical training while service etiquette is the core for the air crew, but many colleges and universities also ignore this in setting courses.

\section{Problems in Actual Teaching of Etiquette to Air Crew}

First, Colleges and universities fail to accurately position courses for air crew and ignore practical training and teaching. Higher education in China mainly focuses on cultivating talents in a short time, and many teachers of air crew just impart theoretical knowledge to students in order to impart service etiquette knowledge to students in a short time while ignoring students' mastery of knowledge. Exams also just check students' theoretical knowledge and ignore practical courses, so although many students can achieve good results in etiquette knowledge, they cannot use them in practice, which hinders their development at work and brings negative influence to the service quality of airline enterprises and even economic loss. More importantly, it is not conducive to students' life and career planning.

Second, low proportion of actual training courses. Service etiquette attaches importance to the adaptation ability with a lot of trivial knowledge in various aspects. Besides, many colleges and universities fail to set sufficient corresponding teaching hours, so it is very difficult for students to not only master theoretical knowledge but also have a high level of practical ability. Not to mention that many colleges and universities set air crew major just in order to quickly end learning of theoretical knowledge, so they cancel practical teaching hours and even if there are practical training courses, they are just on the surface. With limited investment at the school, many students cannot have the chance to practice various actions or the teachers cannot correct wrong actions. Instead, they just spend more time on demonstration while students have few chances to freely practice, thus the quality of teaching etiquette is not good. 
Third, Practical contents are not targeted. Although many colleges and universities cultivate air crew students, they lack connection with airline enterprises, which leads to that the schools teach blindly and do not know the latest development of the industry. Even more, some colleges and universities adopt the traditional teaching mode, which makes practical etiquette courses become boring. Students are tired of study. More importantly, teachers cannot accurately master the practical training contents and meet the aviation industry's demand for students. Students need to study and adapt again at their position.

Fourth, Single practical teaching methods. In actual teaching for air crew majors, many colleges and universities mainly analyze cases or make demonstration. Even if they have the conditions to set actual training lab, they just deliver physical training without creating a real work environment nor simulating targeted career situation, so the effect is not so good.

\section{Measures to Reform Actual Teaching of Etiquette to Air Crew}

First, scientifically position etiquette courses. Development of the aviation industry needs colleges and universities to transmit applied professional talents who can directly work and transfer more theoretical knowledge into professional practical knowledge. Talents' work skills and personal quality is being paid attention to at work. Therefore, while formulating talent cultivating plans, colleges and universities should attach importance to cultivating applied talents and scientifically position etiquette courses and reasonably arrange practical courses according to the teaching contents of etiquette service while increasing the total teaching hours and practical training hours. The best proportion of theoretical course and practical training is $2 / 3$. Colleges and universities should also pay attention to this emerging major. Teachers should be aware of the importance of practical etiquette course, allow students to have space to freely give play to their skills, give them time to think and practice so as to constantly practice their comprehensive service ability.

Second, reasonably integrate teaching contents and design course, projects and tasks. Colleges and universities should actively enhance contact and cooperation with airline enterprises according to their majors and students' learning situation, and invite professional staffs in the aviation industry to deliver speeches to impart their own work experience for professional practical training needed by airline enterprises so as to broaden students' horizons and allow them to have a preliminary and correct understanding of the aviation and service industry. Teachers can also go to nearby airline companies to study the most advanced service etiquette according to the current development and strategies of the aviation industry together with relevant staffs at airline companies so as to make etiquette courses more targeted and practical. In addition, etiquette teachers should also segment relevant etiquette knowledge, formulate different projects and tasks respectively and guide teaching according to tasks so that etiquette teaching can become simple and interested, targeting at students at different levels and students can also easily accept the knowledge.

Third, improve the organization and efficiency of teaching. Colleges and universities should actively support practical etiquette courses for air crew majors, increase investment, improve corresponding practical training conditions and facilities, and simulate practical training base according to the passenger cabin of the aviation industry so that students can feel the authentic simulation scene and make systematical connection so as to effectively improve their service level. Teachers can also divide students into different groups and ask them to play different roles, such as passengers, crew and observers. After students complete each etiquette, they can also exchange their roles. While simulating communication between passengers and the air crew, observers need to observe the acts of air crew and correct their wrong acts. Teachers also need to pay attention to the situation of each group and explain common mistakes among students so as to improve students' enthusiasm in learning etiquette and make them help each other and make common progress.

Four, reform methods of teaching etiquette and improve teaching quality. Teachers should use different teaching methods in the course of teaching etiquette, but not one size fits all, so it is not boring. For example, when teaching grooming, teachers and students can share their make-up experience, can also recommend the student to use cosmetics, for students, but also can guide the student makeup. In teaching cabin service etiquette, teachers can help students to role play, the 
students will be brought into the role of the continuous training of students' service skills. In addition, teachers can also contact and aviation enterprise, make students finish etiquette related content to the corresponding positions of the real aviation enterprise training, let them early work experience, to the real environment, this exercise can help the students go to work to achieve zero distance employment, and continuously improve the comprehensive quality of occupation and form a good habit of occupation etiquette service, has important significance for their future occupation planning.

Fifth, enhance monitoring over practical training and improve etiquette course evaluation system. Colleges and universities should chance the traditional concept of exam. The performance in etiquette exam cannot just be reflected on exam paper, but also in how to use etiquette in practice. Teachers should pay attention to reviewing process, improve the proportion of normal practical training performance in the total score and comprehensively evaluate students according to their actual attendance, training and completion of projects. Review of practical training projects should be completed together by members of student group and teachers. Students can evaluate themselves and others so that the final result can be more objective and accurate, helping teachers to understand students' comprehensive situation.

Six, organize students to actively participate in outdoors air etiquette competition. improve the professional level of skills, the training for the students in many places to carry out training contest, among which is the air etiquette project contest and cabin service skills competition, through competition, to improve the students learning etiquette skills and students' enthusiasm. Schools can also play etiquette related to the game feature film; the school can also hold a small range of etiquette service competition. For example, some schools organize the "blue sky angel" game, and "love in the blue sky" of the game, you can also recommend etiquette top students to television shooting etiquette propaganda, constantly improve the practice ability of students.

Seven, implement the combination of mixed teaching, online classes and actual classes. At present, many courses are flipping the classroom as the main body of the hybrid learning model, also, the teaching of professional flight attendants can also use this way of teaching the advantages of teacher's concept and action guide, flip the classroom is to let the classroom become teachers and students' interaction sites, answering questions of teachers on students. Improve the use of etiquette knowledge; professional flight attendants can be combined with the current network teaching, multimedia teaching and CBT software, the actual operation and project together, building new teaching mode, teaching integration. The class can also practice with WeChat, micro-blog and other students at any time and interactive use, this teaching reform can ignore the limitations of time and space, to know the students, realize the continuity of time and space, to make the course easier to control the interaction between the students, through competition, cooperation and partnership role learning etiquette throughout life.

Eight, Training students' basic cultural and artistic quality, improve the coordination ability. The basic cultural and artistic accomplishment including vocal music, dance and art and so on, through the cultural literacy training, improve their attention to etiquette in addition, indispensable organization and coordination ability and strain capacity is the flight student, analysis of comprehensive capacity of the importance of thinking of continuity and agility, is also the needs of students in the etiquette training, but also to provide a large number of students outside the school social practice activities, students can use the summer vacation time to the aviation business part-time, a basis for future work to lay a solid.

\section{Conclusions}

For many air crew students, service etiquette is a course that needs a long period of study and attaches importance in practice, so only by accumulating massive practical experiences can students smoothly find a job. This brings challenges to colleges and universities' training plan. Schools should constantly update teaching contents according to the actual situation of aviation service, and teachers should also adopt various teaching methods to provide students with a simulated airline environment, regularly organize students to visit and intern at airline companies to accumulate 
practical training experience. Schools can also invite experienced air crew to deliver lectures about the most practical service etiquette at present so as to allow students have a comprehensive understanding of etiquette learning and actively participate in practical training.

\section{References}

[1] Hu Chengfu. "Discussion of Mode to Cultivate Professional Air Crew at Junior Colleges" [J]. Journal of Shaanxi Youth Vocational College, 2009(1).

[2] Higher Education (2006) No.16 Document: "Several Opinions of the Ministry of Education on Comprehensively Improving Teaching Quality of Higher Vocational Education".

[3] "Research into Human Resource Plan and Implementing Talent Strategies at China Aviation" (2012)

[4] China Aviation [2012] No.212 Document.

[5] Zang Yangliu, Xu Ming. Discussion of Modes to Cultivated Professional Air Crew Talents based on Positions [J]. Education and Career, 2014(15):17.

[6] Hu Chengfu. Exploration and Practice of Practical Teaching for Air Crew Majors at Higher Vocational Colleges [J]. Journal of Shaanxi Youth Vocational College, 2013(04):114.

[7] Fan Ruyong, Xiang Xiaole. Analysis of the Concept, Connotation and Development Mode of Career Education Information [J]. Vocational \& Technical Education, 2003, 10.

[8] Yang Guilin. Research of Applying Modern Educational Technologies in Vocational Education [D]. Tianjin University, 2005.

[9] Zhang Jiping. Several Hotspot Issues if Research into Applying Information Technology, China Technology Education, 2002, 1.

[10] Hu Tiesheng: Analysis of the Status Quo of Construction Micro Classes at Colleges and Universities and Research into Development Strategies [J]. Modern Education Technologies,

[11]"Scientific Development Plan of China Aviation during the '12th Five-Year Plan'” 